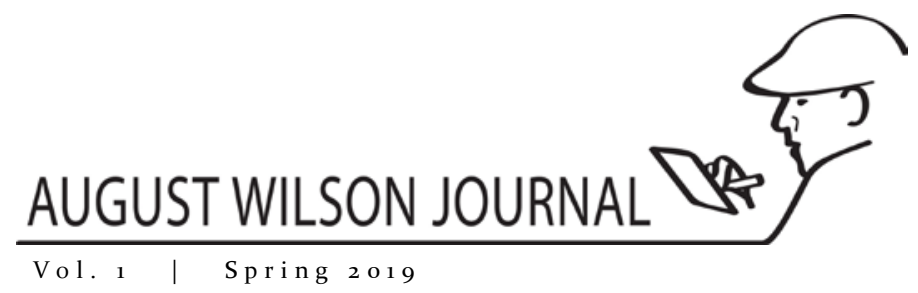

\title{
Stage Review of King Hedley II
}

\author{
Two River Theater; Red Bank, New Jersey \\ Marion Huber Stage \\ November 1o-December 16, 2018 \\ Directed by Brandon Dirden \\ By Cameron Patrick Kelsall \\ Professional Theatre Critic
}

The decision to produce the play on the tiny Marion Huber Stage, which seats fewer than 100 people, drew the audience into the action, causing them to eavesdrop for three sprawling hours.

\section{- Cameron Patrick Kelsall}

\begin{abstract}
A review of King Hedley II by August Wilson, staged at Two River Theater in Red Bank, New Jersey from November 10-December 16, 2018.

Keywords

August Wilson, King Hedley II, Brandon J. Dirden, Hill District, Reaganomics, Signature Theatre Company
\end{abstract}

King Hedley II bears a title that evokes Shakespearean grandeur. Wilson worked on a grand scale throughout his career, but Hedley seems particularly willing to wade into the

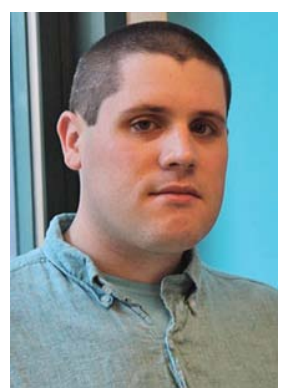

Cameron Kelsall messy questions of lineage, generational trauma, and an uncertain future. These themes occupy Wilson elsewhere in the Century Cycle, but they feel especially centered here, with characters who always have an eye cast toward the past.

Those backward glances may be a reaction to the uncertain times that form the play's setting. King Hedley II takes place in 1985 , amidst the rise of Reaganomics and urban blight. But what may be more troubling than the reality of the country is the diminution of the community in Pittsburgh's Hill District, which no longer holds the vibrant snatches of life it retained even in the grimmest moments of earlier Wilson plays. Instead, "the people wandering all over the place," says the prophetic Stool Pigeon in the prologue. "They got lost. They don't even know the story of how they got from tit to tat."

Brandon J. Dirden's intimate production for Two River Theater (Red Bank, New Jersey) answered the question of how the Hill District got from tit to tat with middling success. The decision to produce the play on the tiny Marion Huber Stage, which seats fewer than 100 people, drew the audience into the action, causing them to eavesdrop for three 
sprawling hours. It reminded the observer that a sense of history hinges on bonds between people, even in grand-scale works.

Dirden, a fine Wilson actor in his own right, returned to Two River after directing Seven Guitars in 2015. (The company has produced five of Wilson's plays since 2012, with plans to complete the full cycle.) His production created a visual world that communicates the playwright's sense of downmarket American life in the mid-eighties. Michael Carnahan's set, dotted with fading Reagan campaign posters and rocky patches of dirt, suggested the crumbling society at the play's core. The two houses at the center, occupied by King (Blake Morris) on one side and Stool Pigeon (Brian D. Coats) on the other, looked proud but worn, like a boxer struggling to find his footing after a knockout punch.

Most of the production's action took place between the houses, with the characters considering how they ended up in this particular spot. King Hedley II serves as a companion to Seven Guitars, with some character overlap and similarities among the protagonists. Although King's nominal father Hedley appears in Seven Guitars, he shares more in common with Floyd Barton, the tragic bluesman whose life and death form the play's narrative. Both men spent time in prison and returned to a changed world where their ambitions couldn't easily be achieved, no matter how they strived. Both men felt caged by their place in society, even while technically free.

But where Floyd operated with smoothness, King leads with unapologetic rage. His ire rises to volcanic levels over seemingly insignificant matters. This presents a challenge that Dirden and Morris didn't always meet. The operatic emotional scale can seem almost comical in its overstatement, but when a production gets it right - as Derrick Sanders' staging for Signature Theatre Company did in 2007 - it's downright terrifying. But Morris, who tended to deliver his lines with breakneck haste, only located King's blinding anger, with little sense of the suffering and disappointment underpinning it. There was little sense of King as the quasi-religious figure Wilson intended, as the repeated image of a halo around his head failed to make the right poignant, metaphorical impression.

That balance of realism and spirituality failed to register throughout Dirden's production. Kathy A. Perkins's high-key lighting literally bleached away the sense of nuance and ambiguity (it also suggested that most scenes take place at exactly the same time every day, contradicting the text.) Stool Pigeon's prophecies came across more like unwanted insertions than necessary commentary tying beginning and end of the play together, largely because Dirden kept Coats separate from the main action. The impetus might have been to paint him as a holy figure existing outside society, but it caused a lack of gravity in crucial moments - as when he announces Aunt Ester's death, which also represents the true death of the community.

This caused the play to dip uncomfortably into melodrama - reinforced by one-note performances from Elain Graham (as Ruby, King's mother) and Brittany Bellizeare (as Tonya, King's long-suffering wife). Wilson gave each woman a rich backstory, which Dirden largely ignored in favor of outsized characterization and overstated line readings. The choice to portray them as semi-comic, almost stock figures severely limited the female perspective of the play - and it dissipated the power of its denouement, which finds King dying by his mother's hand.

It is perhaps not inaccurate to call King Hedley II melodrama - the word, after all, derives from a Greek root meaning music. Like so many of Wilson's works, even when no character actually sings, the poetry hums to a rhythmic beat. Here, the characters lived in prose. The audience came to understand how the Hill got to be a place "all grown over with weeds," as Stool Pigeon describes the once-clear path to Aunt Ester's home. But for a play the balances grace and grit, the telling lacked majesty.

[Editor's Note: This production marks the halfway point in Two River Theater's commitment to stage all ten plays of August Wilson's American Century Cycle.] 
K E L S A L L : S T A G E R E I E W O F K I N G H E D L E Y I I T W O R I V E R THE A T E R, F A L L 2018

August Wilson Journal | Vol. 1 Spring 2019

\section{Works Cited}

Wilson, August. King Hedley II. Theatre Communications Group. 2007.

\section{Author Bio}

Mr. Cameron Patrick Kelsall is a theater critic for the Philadelphia Inquirer and Broad Street Review. $\mathrm{He}$ is also an editor and contributor for the website Exeunt NYC, where he writes about the theater scene in New York City.

\section{Production Photos}

All Photos by T. Charles Erickson

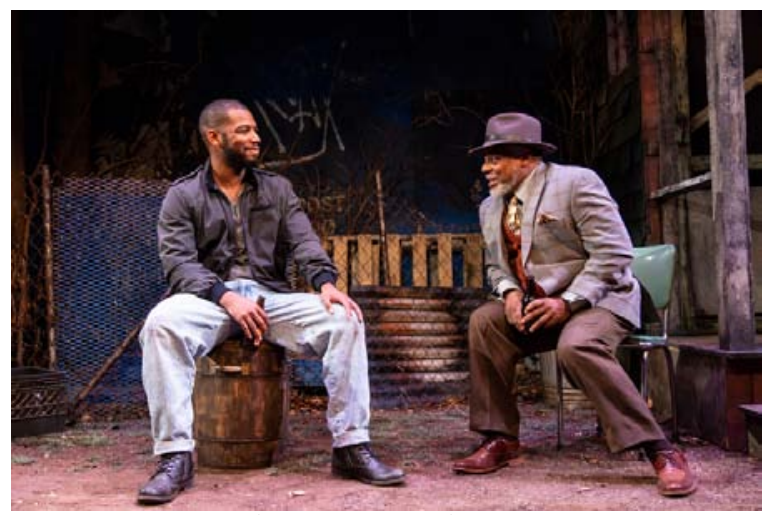

Blake Morris (King Hedley II) and Harvy Blanks (Elmore)
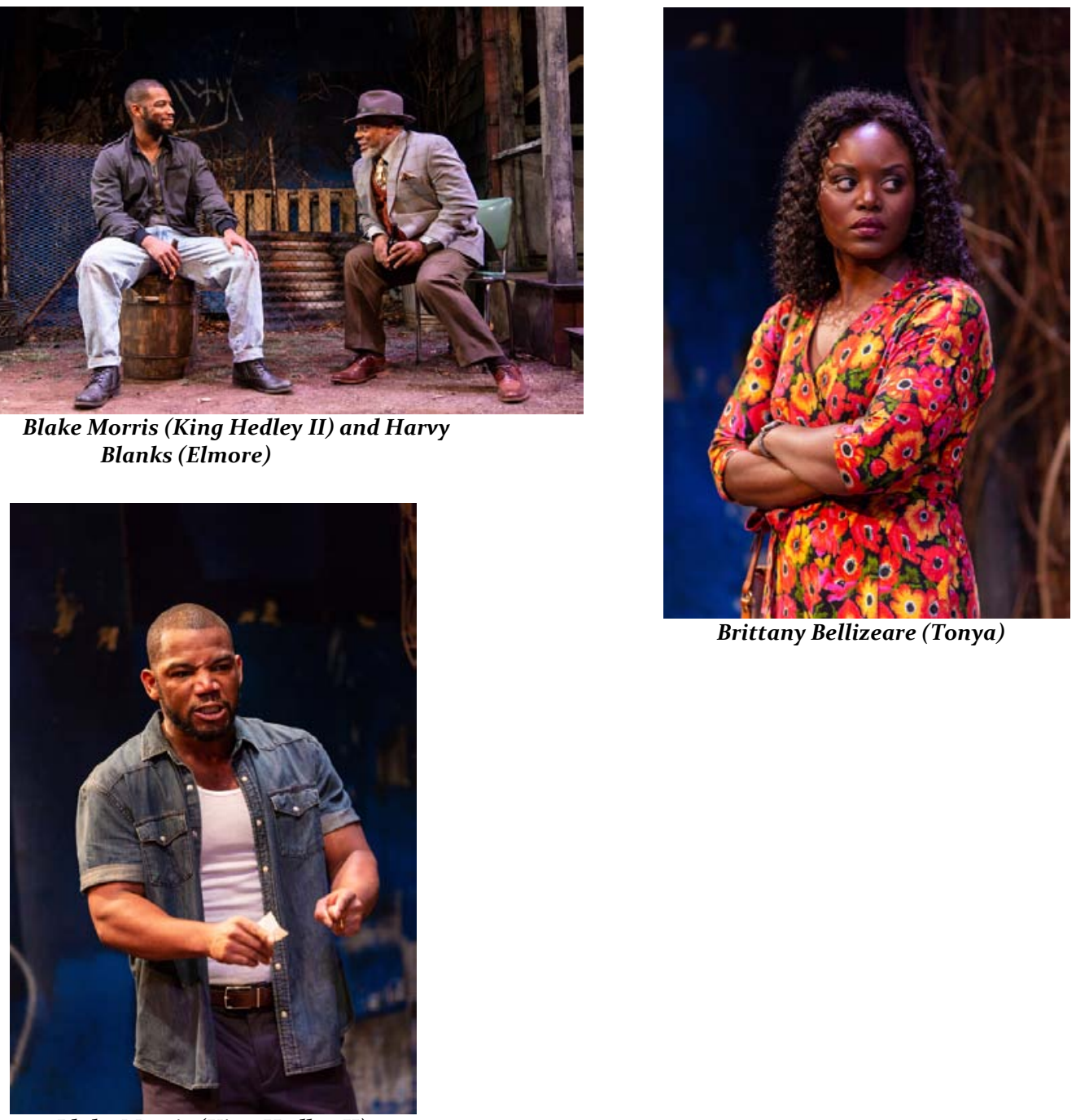

Brittany Bellizeare (Tonya)

Blake Morris (King Hedley II) 

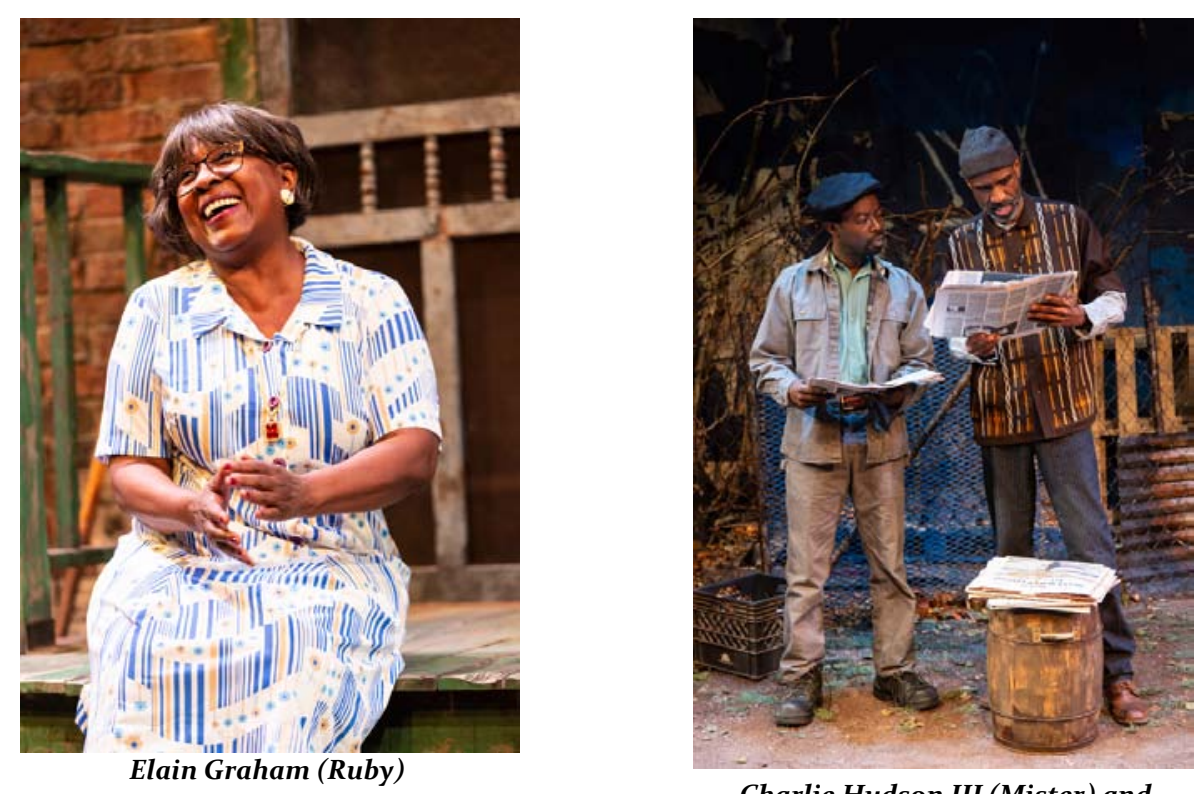

Charlie Hudson III (Mister) and Brian D. Coats (Stool Pigeon) 